\title{
МЕТОДИКА АНАЛИЗА ЭФФЕКТИВНОСТИ ЗАТРАТ НА РАЗВИТИЕ ВЫСОКОТЕХНОЛОГИЧНОЙ МЕДИЦИНСКОЙ ПОМОЩИ
}

\author{
в.В. УГОЛЬНИКОВ
}

Старший преподаватель кафедры «Общая экономическая теория» ФГБОУ ВО «СПбГЭУ», факультет региональной экономики и управления

Статья подготовлена в рамках реализачии проекта 2.2.5 «Проведение научных исследований в сфере потребительских, таможенных и криминалистических услуг населению в рамках научно-образовательного центра «Технологии товароведческой,таможенной $и$ криминалистической экспертизы» Программы стратегического развития ФГБОУ ВПО «СПбГЭУ» на 2014-2016 годы.

\section{Аннотация}

Автор представил методический подход к оценке экономической эффективности услуг здравоохранения по направлению высокотехнологичной медицинской помощи (ВТМП) и построил математическую модель эффективности затрат ВТМП.

Ключевые слова: услуги здравоохранения, высокотехнологичная медицинская помощь, методика, модель, эффективность.

\section{Abstract}

The author presented a methodical approach to assessing the economic effectiveness of health care services in the direction of high-tech medical care (HTMC) and developed a mathematical model of costeffectiveness for HTMC.

Keywords: health care, high-tech medical care, technique, model efficiency.

Развитие медицинских технологий и обеспечение населения высокотехнологичной медицинской помощью (ВТМП) является одним из приоритетных направлений российской экономики. Разработка научно-методических подходов к оценке экономической эффективности услуг здравоохранения по оказанию ВТМП и построение методики анализа эффективности затрат на ВТМП являются актуальными и требующими решения. Цель статьи - рассмотреть ситуацию разделения бюджетных средств финансирования ВТМП по трем возрастным группам населения, включая трудоспособный возраст, младше трудоспособного возраста, старше трудоспособного возраста.

Приоритетом государственной политики РФ до 2020 года является сохранение и укрепление здоровья населения путем формирования здорового образа жизни и повышения доступности и качества медицинской помощи. Основными факторами повышения ее доступности и качества 
названы: совершенствование организационной системы, развитие инфраструктуры и ресурсного обеспечения здравоохранения, кадрового обеспечения инновационного здравоохранения 4 .

Стратегическими целями развития услуг системы здравоохранения являются: прекращение убыли населения РФ; доведение численности до 145 млн. человек; увеличение ожидаемой продолжительности жизни населения до 75 лет; снижение общего коэффициента смертности до 10; снижение показателей младенческой смертности до 7,5 на 1000 родившихся живыми; снижение показателей материнской смертности до 18,6 на 100000 родившихся живыми ${ }^{5}$.

Объектами стратегического внимания отрасли здравоохранения являются: смертность населения РФ и исследование доли заболеваний в общей смертности, изменение численности населения, определение динамики продолжительности жизни в РФ. Доля в общей смертности по заболеваниям в России составляет: болезни системы кровообращения - 56,6\%, из них ишемическая болезнь сердца (ИБС), в том числе инфаркт миокарда (ИМ) - 20\%; болезни сосудов головного мозга, в том числе инсульт - $28 \%$; новообразования - $13,8 \%$; внешние причины смерти - $11,9 \%$; болезни органов пищеварения - 4,2\%; органов дыхания - 3,7\%; инфекционные и паразитарные болезни - 1,6\%, из них туберкулез - 1,4\%. Прочие болезни составляют $8,2 \%$ в доле общей смертности. Из анализа объектов, требующих стратегического внимания государства и общества РФ, следует вывод: смертность населения в России значительно превышает смертность населения в странах Евросоюза и почти $60 \%$ в ней - доля сердечно-сосудистых заболеваний. Следовательно, именно эти заболевания в большей степени влияют на продолжительность жизни в России и тормозят увеличение численности ее населения. Таким образом, вопросы эффективности высокотехнологичной медицинской помощи по профилю сердечно-сосудистой хирургии среди других услуг здравоохранения приобретают особую актуальность, что подтверждается специальными научными исследованиями российских ученых-экономистов, включая направления профилактики, лечения, реабилитации, возвращения к труду.

Важность системного и комплексного анализа для принятия обоснованных решений по формированию среды оказания экономически эффективной ВТМП в условиях инновационного развития сферы услуг здравоохранения, сохранение дискуссионности в теоретико-прикладных аспектах рассматриваемых в настоящей работе вопросов предопределили актуальность сформулированной ее темы. При этом поставлена задача разработки методического подхода к оценке экономической эффективности услуг здравоохранения по направлению ВТМП, построения методики и математической модели эффективности затрат на расширение ВТМП для развития капитала здоровья населения.

Наиболее перспективными считаются высокотехнологичные методы лечения. Базой оказания такой высокотехнологичной помощи (ВТМП) являются специализированные, как правило, государственные медицинские учреждения федерального уровня, региональные клиники,

4 Концепция развития системы здравоохранения в Российской Федерации до 2020 г.[ Электронный ресурс]. URL: http://topmedicina.ru/health/koncepciya/ (дата обращения 21.12.2013).

5 Там же 
а также частные клиники. Эти лечебные учреждения иногда становятся участниками новых структур, создаваемых в регионах для повышения конкурентоспособности их экономик.

Экономико-математический подход к решению вышеназванных проблем состоит в оптимизации бюджетного финансирования программ ВТМП. Повышение эффективности услуг здравоохранения, включая ВТМП, не означает простого сокращения затрат. Эффективность - мера качества и (или) количества результатов, получаемой при заданном уровне входящих ресурсов. Первая является показателями здоровья или услуг, вторые - затратами. Повышение эффективности действительно может достигаться снижением расходов на услуги здравоохранения.

Источники неэффективности здравоохранения ${ }^{6}$ связаны с лекарственными препаратами, кадровыми проблемами и услугами здравоохранения, такими как: чрезмерное использование или поставки оборудования, исследований и процедур; необоснованная госпитализация или продолжительность пребывания в стационаре; ненадлежащий размер больницы, недостаточное использование инфраструктуры; врачебные ошибки и некачественное оказание помощи; неэффективный пакет, неподходящий уровень стратегии.

Медицинские технологии играют решающую роль при оказании медико-санитарных услуг. Современные медицинские технологии - главный фактор растущих расходов стран Организации экономического сотрудничества и развития (ОЭСР), и величина, на которую ориентируется каждая страна. Япония лидирует по количеству МРТ и КТ томографов на душу населения; США - по количеству диагностических, визуализирующих исследований (91,2 на 1000 человек против 41,3 в среднем по странам ОЭСР). Другая крайность - 50\% медицинской техники частично или полностью непригодна к использованию (в странах Африки). Кроме того, высокие расходы на здравоохранение не гарантируют снижение уровня смертности, улучшения функционального состояния или повышения удовлетворенности услугами. Действительно, в ряде регионов США жители получают на $60 \%$ больше медицинской помощи, но там нет снижения уровня смертности ${ }^{7}$. Это свидетельствует о возможностях уменьшения расходов и повышения эффективности 5 .

На анализе более 300 международных исследований установлено, что экономическая эффективность больницы составляет $85 \%$. То есть, больницы могли бы оказать услуг на $15 \%$ больше при тех же затратах, или же снизить затраты на 15\% и оказать тот же объем услуг. Сумма, потерянная вследствие неэффективности работы больниц, приводит к потерям ежегодно в 300 млрд. долл. США независимо от региона мира.

Потенциальная экономия от повышения эффективности с разбивкой по затратам и уровня дохода страны может быть представлена через компоненту медицинских услуг, как причина неэффективности услуг здравоохранения. Фактор человеческие ресурсы в компоненте медицинские услуги приводит к экономии от повышения эффективности для всего населения в размере - $1100-$

6 Финансирование систем здравоохранения. Путь к всеобщему охвату населения медико-санитарной помощью. Доклад Всемирной организации здравоохранения, 2010 г. [Электронный ресурс]. URL: http://www.inpharm.ru/assets/files/voz-zdravoohranenie2010.pdf, c.65.

7 Там же, с.66.

5 Дроздов Г.Д. Интегрированная информационная система университетского комплекса: монография, с. 15 
851млрд. долл. США. Фактор больницы в этом же компоненте 54 - 503 млрд. долл. США, пакет вмешательств 141 - 1094 млрд. долл. США и неэкономное использование ресурсов - 51 - 468 млрд. долл. США

В результате, вследствие неэффективности теряется от 20\% до $40 \%$ всех расходов на здравоохранение, что подтверждает актуальность проблемы сокращения неэффективности. Непосредственно снижение неэффективности не обязательно предполагает сокращение расходов, неэффективность может происходить также от излишних расходов.

На современном этапе развития экономики решением проблем здравоохранения по доступности, качеству и экономической эффективности медицинской помощи являются финансовые инструменты, жесткий контроль за распределением финансовых средств, что лежит в основе повышения экономической эффективности в сфере услуг здравоохранения.

Необходимо учитывать, что увеличение средств для здравоохранения не гарантирует каждому незамедлительный доступ ко всем услугам здравоохранения для улучшения состояния здоровья, поскольку существует проблема ресурсных ограничений. Так для примера, национальная служба здравоохранения в Британии в 2009 г. не имела возможности представить бесплатно дорогостоящие лекарственные средства по ряду заболеваний в виду экономической нецелесообразности: инновационные фармацевтические препараты, диагностические лечебные технологии появляются на рынке быстрее, чем финансовые ресурсы. Невозможно обеспечить все население существующими прогрессивными медицинскими технологиями и вмешательствами по улучшению здоровья и продлению жизни. При этом финансовые вложения в здравоохранение в экономически развитых странах довольно высоки: в год на душу населения тратится в США и Норвегии более 7000 долл. США, в Швейцарии - более 6000 долл. США, странах Организации экономического сотрудничества и развития (ОЭСР) - около 3600 долл. США. Основу этих финансовых решений определяет увеличение доли пожилого населения и сокращение численности рабочей силы.

Важным показателем, характеризующим уровень развития здравоохранения на макро- и мегауровне является доступность медицинской помощи. По данным экспертов ВОЗ, главными барьерами доступности медицинской помощи являются бедность населения и проблемы транспортной доступности (Республика Молдова).

Выскажем предположение, что высвобождающиеся для здравоохранения ресурсы могут быть нацелены на повышение эффективности в какой-то отдельной области здравоохранения, например, развитие высокотехнологичной медицинской помощи населению.

В связи с непрерывно растущими затратами на здравоохранение и увеличением спроса на услуги здравоохранения, в особенности, высокотехнологичного сектора, проблема их эффективности, как и системы здравоохранения в целом - важная национальная задача любого государства. Подчеркнем, что повышение эффективности не всегда означает простого сокращения затрат.

Известны модели оценки экономической эффективности здравоохранения в соответствии с типом экономического анализа на основе объединения типа анализа, соответствующей ему 
расчетной формулы, определенных расчетных величин и критериев оценки. К типам анализа отнесены: стоимость болезни, минимизация затрат, затраты-эффективность, затраты-полезность, затраты-выгода. Так, расчетная формула для первого из перечисленных типов анализа - COI = DC + $+1 \mathrm{C}$ (тариф $\left.=\mathrm{COI}_{1}+\mathrm{COI}_{2}+. .+\mathrm{COI}_{n}\right)$, где расчетными величинами являются $\mathrm{CO}-$ показатель стоимости болезни; DC - прямые затраты; 1C - косвенные затраты; $\mathrm{n}$ - число пациентов. При этом критерием служит полная стоимость лечения болезни на различных этапах.

Для проведения оценки качества и эффективности стационарной помощи учреждений здравоохранения применяются методы: экспертных оценок, опросный, статистический, комплексный анализ (Таблица 1).

Таблица 1

\begin{tabular}{|c|c|c|}
\hline Метод & Объект оценки & Область применения \\
\hline Статистический & $\begin{array}{l}\text { 1. Ресурсы (кадры, } \\
\text { финансирование, материально- } \\
\text { техническое обеспечение). } \\
\text { 2. Объёмы работы (нагрузка). } \\
\text { 3. Качество медицинской помощи. }\end{array}$ & $\begin{array}{l}\text { 1. Оценка эффективности } \\
\text { результатов работы. } \\
\text { 2. Планирование деятельности. } \\
\text { 3. Обоснование потребности } \\
\text { в ресурсах }\end{array}$ \\
\hline Экспертных оценок & $\begin{array}{l}\text { 1. Ресурсы (кадры, материально- } \\
\text { техническая база). } \\
\text { 2. Выбор и применение } \\
\text { медицинских технологий, их } \\
\text { соответствие стандартам, } \\
\text { эффективность медицинской } \\
\text { помощи. }\end{array}$ & $\begin{array}{l}\text { 1. Оценка объёма и качества } \\
\text { медицинской помощи. } \\
\text { 2. Организация клинико-экспертной } \\
\text { работы. } \\
\text { 3. Планирование деятельности. } \\
\text { 4. Лицензирование и аккредитация. }\end{array}$ \\
\hline $\begin{array}{l}\text { Медико- } \\
\text { экономического } \\
\text { анализа }\end{array}$ & $\begin{array}{l}\text { 1. Объём плановых и фактических } \\
\text { затрат на медицинскую помощь, } \\
\text { нагрузка врачей. } \\
\text { 2. Использование ресурсов } \\
\text { (включая нагрузку медицинского } \\
\text { персонала). }\end{array}$ & $\begin{array}{l}\text { 1. Оценка эффективности. } \\
\text { 2. Контроль объёмов и } \\
\text { качеств* медицинской помощи. } \\
\text { 3. Оценка объёмов работы, оплаты } \\
\text { труда. } \\
\text { 4. Обоснование потребности в } \\
\text { финансировании ЛПУ }\end{array}$ \\
\hline Опросный & $\begin{array}{l}\text { Степень удовлетворенности } \\
\text { населения качеством медицинской } \\
\text { помощи }\end{array}$ & $\begin{array}{l}\text { Планирование мероприятий по } \\
\text { улучшению качества медицинской } \\
\text { помощи }\end{array}$ \\
\hline $\begin{array}{l}\text { Комплексный } \\
\text { (комбинированный) }\end{array}$ & $\begin{array}{l}\text { Объём и качество медицинской } \\
\text { помощи с применением } \\
\text { информационных технологий, с } \\
\text { использованием стандартов, } \\
\text { квалиметрии }\end{array}$ & $\begin{array}{l}\text { Планирование мероприятий по } \\
\text { улучшению качества медицинской } \\
\text { помощи. }\end{array}$ \\
\hline
\end{tabular}

Для дальнейших рассуждений рассмотрим различные возрастные группы населения по следующим возрастам: ниже трудоспособного возраста, трудоспособного возраста и старше трудоспособного возраста. Построим математическую модель эффективности затрат на развитие высокотехнологичной медицинской помощи для этих трех возрастных групп населения, для чего распределим финансирование ВТМП, составляющее в году $t N(t)$ руб. по трем указанным возрастным группам: 
$X j(t)$ - объем финансирования групп, возраст которых в году $t$ меньше трудоспособного, в пределах трудоспособного и выше трудоспособного возраста, т.е. $j$ пробегает целые значения от 1 до 3 и ) $\left.\sum_{1}^{3} X_{j}(t)\right) \leq N(t)$.

Если $\alpha_{j}(t)$ - стоимость ВТМП для излечения одного человека в данных возрастных группах для целочисленных $j$ от 1 до 3 соответственно в году $t$, то среднее число возвращенных к трудовой деятельности больных равно $\frac{x_{j}(t)}{\alpha_{j}(t)}$, где $j$ принимает значения 1,2,3. Если от возвращения одного больного из каждой возрастной группы $j$ (в году $t$ ) $\beta_{j}(t)$ есть экономическая выгода, то целевая функция, определяющая экономическую эффективность ВТМП, имеет вид:

$$
Z\left(X_{1}, X_{2}, X_{3}, t\right)=\sum_{1}^{3} X_{j}(t) \times \frac{\beta_{j}(t)}{\alpha_{j}(t)}
$$

Нахождение максимума целевой функции и соответствующей оптимальной стратегии $X^{*}\left(X_{1}^{*}(t), X_{2}^{*}(t), X_{3}^{*}(t)\right)$ представляет процедуру анализа эффективности затрат в направлении ВТМП и лежит в основе разработки методики анализа эффективности затрат ВТМП для оптимизации капитала здоровья населения:

-Определить средние стоимости $\alpha_{j}(t)$ излечения одного человека в трех возрастных группах.

-Вычислить параметры $\beta_{j}(t)$ для рассматриваемых трех возрастных групп.

-Вычислить предельные значения для трех возрастных групп.

-Вычислить значения целевой функции.

-Выбрать наибольшее из значений.

Выводы. Экономические потери здоровья населения определяют потери капитала здоровья в денежном выражении. Расширяя оказание услуг в секторе высокотехнологичной медицинской помощи, становится возможным оценить их экономическую эффективность путем разработки соответствующей методики, что стало результатом проведенного и представленного выше исследования.

\section{ЛИТЕРАТУРА}

2. Концепция развития системы здравоохранения в Российской Федерации до 2020 г.[ Электронный ресурc]. URL: http://topmedicina.ru/health/koncepciya/.

3. Финансирование систем здравоохранения. Путь к всеобщему охвату населения медико-санитарной помощью. Доклад Всемирной организации здравоохранения, 2010 г. [Электронный ресурс]. URL: http://www.inpharm.ru/assets/files/voz-zdravoohranenie2010.pdf.

4. Прохоров Б.Б., Иванова Е.И., Шмаков Д.И., Щербакова Е.М. Медикодемографическое прогнозирование. - М.: МАКС Пресс, 2011. - 356 с.

5. Угольников В.В. Государственно-частное партнерство. Развитие высокотехнологичной медицинской помощи: монография / О.Д. Угольникова, А.П. Петров, В.В. Угольников. Государственно-частное партнерство как условие конкурентного развития экономики / ред. Дроздов Г.Д., д.э.н., проф., Угольникова О.Д., к.ф.-м.н., доц. - СПб. : Изд-во СПбГУСЭ, 2013. - 179 c. (С. 52-83). 
6. Дроздов, Г.Д. Интегрированная информационная система университетского комплекса: монография / Г.Д. Дроздов, С.А.Бражников; М-во образования и науки Российской Федерации, Санкт-Петербургский университет сервиса и экономики. Санкт-Петербург, 2010. $163 \mathrm{c}$. 